\title{
Ternary Nanocomposites: Curing, Morphology, and Mechanical Properties of Epoxy/Thermoplastic/ Organoclay Systems
}

\author{
M. Sánchez-Cabezudo, ${ }^{1}$ M.G. Prolongo, ${ }^{2}$ C. Salom, ${ }^{2}$ M.A. García del Cid, ${ }^{2}$ R.M. Masegosa ${ }^{1}$ \\ ${ }^{1}$ Dpt. Física y Química Aplicadas a la Técnica Aeronáutica., Univ. Politécnica de Madrid, Spain
}

${ }^{2}$ Dpt. Materiales y Producción Aeroespacial., Univ. Politécnica de Madrid, Spain

The influence of two organically modified montmorillonites on the curing, morphology and mechanical properties of epoxy/poly(vinyl acetate)/organoclay ternary nanocomposites was studied. The organoclays and poly(vinyl acetate) (PVAc) provoked contrary effects on the epoxy curing reaction. Ternary nanocomposites developed different morphologies depending on the PVAc content, that were similar to those observed in the epoxy/PVAc binary blends. The organoclays were only located in the epoxy phase independently of the morphology. All nanocomposites showed intercalated structures with similar clay interlayer distances. Both PVA $_{C}$ and organoclays lowered the $T_{\mathrm{g}}$ of the epoxy phase, the presence of clays did not influence the $T_{\mathrm{g}}$ of the PVAc phase. The addition of the organoclays to the epoxy improved stiffness but lowered ductility while the adition of PVAc improved toughness although reduced stiffness of epoxy thermoset. Ternary nanocomposites exhibited optimal properties that combine the favourable effects of the clay and the thermoplastic. POLYM. COMPOS., 00:000000, 2015. 2015 Society of Plastics Engineers

\section{INTRODUCTION}

Polymer nanocomposites offer the possibility to achieve significant enhancements in material properties with much lower filler content than conventional composites [1-3]. Montmorillonite (MMT) is the layered silicate most widely used in polymer nanocomposites. MMT consists on layers of one nanometer thick and several hundreds nanometers long and wide, these platelets are stacked forming tactoids, which are grouped forming aggregates. MMT clay is modified through cationic exchange by replacing the inorganic cations, which are located in the interlayer gallery, with alkyl ammonium cations. These organoclays can intercalate organic molecules and hydrophobic polymer molecules inside the galleries [1-3]. The dispersion of clay platelets in a polymer can noticeably improve its mechanical properties (modulus and strength) and barrier properties (gas and solvent transport) [1-3].

Epoxy thermosets are widely used in many applications such as structural components, adhesives and coatings, owing to their high chemical and solvent resistance, good thermal and mechanical properties, high creep resistance, low shrinkage, and excellent adhesion to metals and ceramic materials. Epoxy/organoclay nanocomposites have been investigated over the past years [4-13], their properties depend on the composition (types of curing agent and epoxy prepolymer) cure temperature, type of organoclay, clay content, and the processing method.

Since most epoxy thermosets are intrinsically brittle, they are toughened through incorporation of thermoplastics or elastomers [14]. For most systems the initial mixture is miscible but as the curing reaction progresses a phase separation takes place. The final morphology (size and distribution of the epoxy and thermoplastic domains) is determined by the composition (thermoplastic content) and cure temperature, and the properties of the modified epoxy depend on the morphology generated [14-17].

The influence of nanoparticles on phase behavior and morphology of polymer blends, and the distribution of nanoparticles inside the blend are topics of interest. Indeed it is known that the presence of nanoparticles can affect the phase separation behavior and the morphology of polymer blends [18, 19]. Moreover it has been shown that in some cases the introduction of nanoparticles into a monomer mixture before reaction increases the compatibility of the polymers formed on polymerization [19]. Most of these studies are focused on blends of linear 
polymers. Less attention had been paid to the influence of nanoparticles on the properties of ternary nanocomposites which include a thermoset polymer, and in particular of those formed by epoxy/thermoplastic/nanoparticles originated by reaction induced phase separation. Epoxy nanocomposites containing a rubber and an inorganic reinforcement have been investigated with the objective of improving mechanical and thermal properties of the polymer matrix [20-24]. Some works have studied epoxy/ thermoplastic/clay ternary systems [25-35], but only few of them deal with the influence of nanoclays on the morphology generated during curing as a function of the thermoplastic content $[31,35]$.

This work is aimed at studying the effect of organoclay particles on curing, on the reaction induced phase separation and on mechanical properties of an epoxy/thermoplastic/organoclay system. In previous works we have studied epoxy/poly(vinyl acetate) (PVAc) blends [16, 36] and epoxy/MMT nanocomposites [37, 38]. The ternary nanocomposites here studied are formed by epoxy/monmorillonite/PVAc using as nanoparticles two organically modified MMTs (Cloisite 30B and Cloisite 93A). These two clays have been selected because they have different hydrophobicity due to the different organic modifier.

\section{EXPERIMENTAL}

\section{Materials}

The epoxy monomer, diglycidyl ether of bisphenol A (DGEBA) was supplied by Ciba (Spain) under the commercial name of Araldit F. The number average relative molecular mass, $\bar{M}_{n}=360 \mathrm{~g} \cdot \mathrm{mol}^{-1}$, was obtained by chemical titration of the end groups. The curing agent, 4,4'-diamino diphenylmethane (DDM) (97 wt\%) was supplied by Acros Organics (Belgium). A stoichiometric ratio of DGEBA to DDM was used to prepare the samples. The PVAc with $\overline{\mathbf{M}}_{n}=9 \cdot 10^{4} \mathrm{~g} \mathrm{~mol}^{-1}$ and polydispersity index 2 was supplied by Polysciences (UK).

The organophilic clays: Cloisite 30B (C30B) and Cloisite 93A (C93A) were supplied by Southern Clay Products (TX, USA). These organoclays are modified with quaternary alkyl ammonium cations. In C93A the alkyl ammonium cations have one acidic hydrogen atom, one methyl group and two alkyl chains, whereas in C30B the ammonium cations have one methyl group, two hydroxylethyl groups and one alkyl chain, in both clays the alkyl chains have: $\sim 65 \% \mathrm{C}_{18}, \sim 30 \% \mathrm{C}_{16}$, and $\sim 5 \% \mathrm{C}_{14}$. The modifier concentration or cation exchange capacity (CEC) is $90 \mathrm{meq} / 100 \mathrm{~g}$ clay. The moisture content is less than 2 wt \%. Frekote from Loctite (Spain) was employed as mould release product.

\section{Preparation of Clay Dispersions and Nanocomposites}

DGEBA-PVAc mixtures were prepared by dissolving PVAc in DGEBA at $90^{\circ} \mathrm{C}$ using magnetic stirrer for $4 \mathrm{~h}$.
Dispersions of clays were prepared by adding the organoclay powders to DGEBA or to DGEBA-PVAc mixtures, stirring at $300 \mathrm{rpm}$ at $90^{\circ} \mathrm{C}$ for $18 \mathrm{~h}$. The dispersions were degassed for about $1-2 \mathrm{~h}$ under vacuum at $120^{\circ} \mathrm{C}$. Then the curing agent (DDM) melted and degassed was added and mixed at $100^{\circ} \mathrm{C}$ with stirring during $5 \mathrm{~min}$. These dispersions were used:

(a) To study the influence of the clay on curing by the differential scanning calorimetry (DSC). (b) To prepare specimens of nanocomposites, to do that, the dispersions were poured into aluminum moulds whose walls were previously treated with mould release product, and cured in an oven. According to previous works $[16,17,36]$ the curing protocol used was: $120^{\circ} \mathrm{C}$ during $2 \mathrm{~h}$, then the temperature was raised to $180^{\circ} \mathrm{C}$ (it took about $30 \mathrm{~min}$ ) and kept at $180^{\circ} \mathrm{C}$ for $30 \mathrm{~min}$. The curing was carried out under atmospheric pressure.

The content of clay in dispersions and nanocomposites was 4 wt $\%$ and the PVAc content varies from 0 to $20 \mathrm{wt} \%$.

\section{DSC}

A Mettler Toledo $822 \mathrm{e}$ differential scanning calorimeter was used to measure the heats of the curing reaction and the glass transition temperatures. The instrument was calibrated with indium and zinc and the measurements were registered at a heating rate of $10^{\circ} \mathrm{C} \mathrm{min}{ }^{-1}$ under nitrogen atmosphere. The scans ranged from -50 to $320^{\circ} \mathrm{C}$. A M4 Sartorius microbalance was used to weigh the samples of about $10-20 \mathrm{mg}$ ( $\pm 0.001 \mathrm{mg}$ ). The $T_{\mathrm{g}}$ 's were taken at the midpoint of the heat capacity change.

\section{Wide-Angle X-Ray Diffraction (WAXD)}

Wide angle X-ray diffraction patterns of the nanocomposites were obtained at room temperature in reflection mode using a Panalytical X'Pert PRO Alphal diffractometer equipped with a curved Ge111 primary beam monochromator and a fast detector X'Celerator ( $\mathrm{Cu} K \alpha 1$ radiation $(\lambda=0.15406 \mathrm{~nm}), 45 \mathrm{kV}, 40 \mathrm{~mA})$. The measurement range of $2 \theta$ was from $1.5^{\circ}$ to $40^{\circ}$, and step size $0.0167^{\circ}$.

\section{Dynamic Mechanical Thermal Analysis (DMTA)}

Dynamic mechanical thermal analysis (DMTA) of the nanocomposites was performed in dual cantilever bending mode using a DMTA V Rheometric Scientific instrument. Measurements were done at $1,2,6,10$, and $40 \mathrm{~Hz}$, with temperature increasing from $30^{\circ} \mathrm{C}$ to $220^{\circ} \mathrm{C}$ at a heating rate of $1^{\circ} \mathrm{C} \min ^{-1}$. Specimens dimensions were: $35 \times 10$ $\times 1.8 \mathrm{~mm}^{3}$. The elastic or storage modulus $\left(E^{\prime}\right)$, the loss modulus $\left(E^{\prime \prime}\right)$, and loss tangent $(\tan \delta$ ) isochrones as a function of temperature were recorded. The maxima in $\tan \delta$-temperature plots were determined to identify the $\alpha$-relaxations associated to the glass transitions. 


\section{Tensile Tests}

Tensile mechanical properties of the nanocomposites were measured using a MTS machine, QTest 2L model, and a MTS extensometer, model number 63411F-54, with $2 \mathrm{kN}$ load cell capability. The experiments were conducted at room temperature $\left(22^{\circ} \mathrm{C}\right)$. The specimens $(140$ $\times 10 \times 1.8 \mathrm{~mm}^{3}$ ) were loaded at constant rate of $1 \mathrm{~mm}$ $\min ^{-1}$ until fracture. Stress-strain curves were recorded for six or more specimens of each composition to obtain the average value of the mechanical properties: tensile modulus, tensile strength, strain at break and toughness that was determined by integrating area under the curve of engineering stress versus engineering strain.

\section{Morphological Characterization}

The morphology of the nanocomposites was studied through scanning electron microscopy (SEM) and transmission electron microscopy (TEM). For SEM experiments a Phillips XL30 instrument and a Nova NanoSEM 230 FEI (FEG) instruments were employed with beam energy of 3$30 \mathrm{kV}$. The samples were cryogenically fractured and the fracture surfaces of the samples were coated with gold (12-15 nm of thickness) by vapor deposition using a vacuum sputter. For TEM experiments ultrathin samples were cut from specimens using an ultramicrotome equipped with a diamond knife. The microtomed samples were laid onto mesh copper grids and scanned in a JEOL (JEM 2100HT) transmission electron microscope with resolution of $25 \mathrm{~nm}$.

\section{RESULTS AND DISCUSSION}

\section{Dynamic Curing of Epoxy/PVAc/Cloisite Dispersions by $D S C$}

Figure 1 shows the DSC thermograms for the dispersions of C93A and C30B in DGEBA-DDM-PVAc blends with different PVAc content. We had previously studied the curing of DGEBA-DDM-PVAc blends [36], but in order to compare systems with and without organoclay new measurements have been done using the same materials, the same contents of PVAc and the same protocol of mixing. The DSC thermograms obtained are also shown in Fig. 1. The glass transition of the unreacted blend $\left(T_{\mathrm{g}}{ }^{0}\right)$ appears around $-10^{\circ} \mathrm{C}$ and is followed by the exothermic peak of the curing reaction. The exothermic peaks shift to higher temperatures with increasing PVAc content both in the DGEBA-DDMCloisite-PVAc dispersions and in the DGEBA-DDM-PVAc blends. These shifts reflect a slowdown of the curing reaction due to the dilution effect of PVAc which is in accordance with our previous results [36].

The values of $T_{\mathrm{g}}{ }^{0}$, of the peak temperature $\left(T_{\text {peak }}\right)$ and of the reaction enthalpy $(\Delta H)$ calculated from the peak area, are quoted in Table 1 . The results show that the addition of clay increases $T_{\mathrm{g}}{ }^{\circ}$. This behavior is in accordance with the previously reported for DGEBA-DDM-
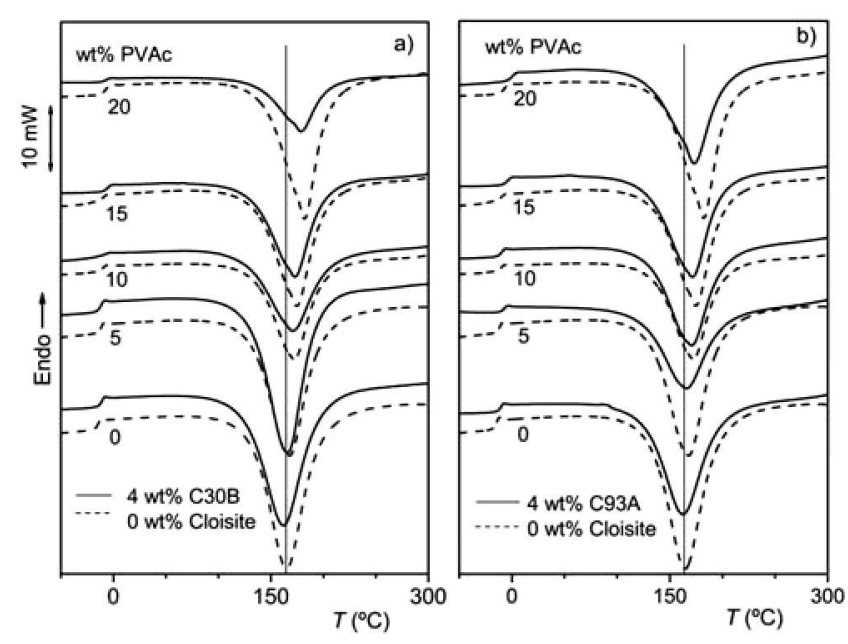

FIG. 1. DSC thermograms of: (a) DGEBA-DDM/PVAc/C30B and (b) DGEBA-DDM/PVAc/C93A dispersions with different PVAc contents. For comparison the thermograms of DGEBA-DDM/PVAc blends (dash lines) are included in (a) and (b).

C30B dispersions [37] and could suggest that some DGEBA molecules have homopolymerized (catalyzed by the clay) during the dispersion preparation. Moreover the increase of $T_{\mathrm{g}}{ }^{0}$ may reflect good interactions between the Cloisites and the uncured epoxy resin. On the other hand the $T_{\mathrm{g}}{ }^{0}$ of the $\mathrm{C} 30 \mathrm{~B}$ and $\mathrm{C} 93 \mathrm{~A}$ dispersions increases with rising PVAc content, following a similar trend than DGEBA-DDM-PVAc blends (0\% clay), whose behavior is the expected for miscible blends, that is, $T_{\mathrm{g}}$ of the blends is between $T_{\mathrm{g}}$ of the components ${ }_{[} T_{\mathrm{g}}{ }^{0}$ (DGEBADDM $)=-15^{\circ} \mathrm{C}$ and $\left.T_{\mathrm{g}}(\mathrm{PVAc})=44^{\circ} \mathrm{C}\right]$.

$T_{\text {peak }}$ values are lower in presence of $\mathrm{C} 93 \mathrm{~A}$ or $\mathrm{C} 30 \mathrm{~B}$ this means that the curing reaction is accelerated in the presence of the clays, as we reported previously for DGEBA-DDM-clay dispersions without thermoplastic [37, 38]. Similar Catalytic effect of organoclays has been reported for other epoxy-clay systems $[4-8,10]$.

The released heat of reaction $(-\Delta H)$ decreases with the addition of organoclay, $\mathrm{C} 30 \mathrm{~B}$ or C93A. This agrees with the hypotheses previously stated [38] of stoichiometric imbalances originated by the presence of clay. The stoichiometric imbalances between DGEBA and DDM can be produced by selective intercalation of DGEBA into the clay galleries and by epoxy homopolymerization produced during the dispersion preparation. Therefore the addition of the organoclays affects the network formation. Besides, $-\Delta H$ decreases by increasing the content of PVAc, although the decrease by the presence of PVAc is significantly lower than by the clays (4 wt\% clay is equivalent to $20 \mathrm{wt} \%$ PVAc). The influence of PVAc in $\Delta H$ is only significant for $20 \mathrm{wt} \%$ PVAc content.

\section{WAXD of Epoxy/PVAc/Cloisite Cured Nanocomposites}

Figure $2 \mathrm{a}$ shows the WAXD patterns of $\mathrm{C} 30 \mathrm{~B}$ and C93A clays. It can be seen that the (001) diffraction peak of these clays appears at $2 \theta=4.84^{\circ}$ and $3.45^{\circ}$ which 
TABLE 1. DSC results for dispersions of C93A and C30B in DGEBA-DDM/PVAc blends: $T_{\mathrm{g}}{ }^{0}, T_{\text {peak }}$ and $\Delta H$ (reaction enthalpy released referred to the epoxy equivalent).

\begin{tabular}{|c|c|c|c|c|c|c|c|c|c|}
\hline \multirow[b]{2}{*}{$\mathrm{wt} \%$ PVAc } & \multicolumn{3}{|c|}{$T_{\mathrm{g}}^{0}\left({ }^{\circ} \mathrm{C}\right)$} & \multicolumn{3}{|c|}{$T_{\text {peak }}\left({ }^{\circ} \mathrm{C}\right)$} & \multicolumn{3}{|c|}{$\Delta H(\mathrm{~kJ} / \mathrm{ee})$} \\
\hline & $0 \%$ clay & $4 \mathrm{wt} \% \mathrm{C} 30 \mathrm{~B}$ & 4 wt\% C93A & $0 \%$ clay & $4 \mathrm{wt} \% \mathrm{C} 30 \mathrm{~B}$ & $4 \mathrm{wt} \% \mathrm{C} 93 \mathrm{~A}$ & $0 \%$ clay & $4 \mathrm{wt} \% \mathrm{C} 30 \mathrm{~B}$ & $4 \mathrm{wt} \% \mathrm{C} 93 \mathrm{~A}$ \\
\hline 0 & -15 & -12.0 & -11 & 164 & 163 & 162 & 105 & 97 & 97 \\
\hline 5 & -12 & -12 & -8 & 168 & 166 & 166 & 105 & 101 & 99 \\
\hline 10 & -12 & -11 & -10 & 172 & 172 & 171 & 100 & 97 & 99 \\
\hline 15 & -12 & -6 & -5 & 175 & 173 & 172 & 101 & 96 & 96 \\
\hline 20 & -8 & -7 & -1 & 182 & 180 & 171 & 97 & 90 & 91 \\
\hline
\end{tabular}

corresponds to a basal spacing $\left(d_{001}\right)$ of $=1.85 \mathrm{~nm}$ for $\mathrm{C} 30 \mathrm{~B}$ and $2.36 \mathrm{~nm}$ for $\mathrm{C} 93 \mathrm{~A}$ as calculated from Bragg's law. The small peaks at $2 \theta=9.60^{\circ}$ for $\mathrm{C} 30 \mathrm{~B}$ and

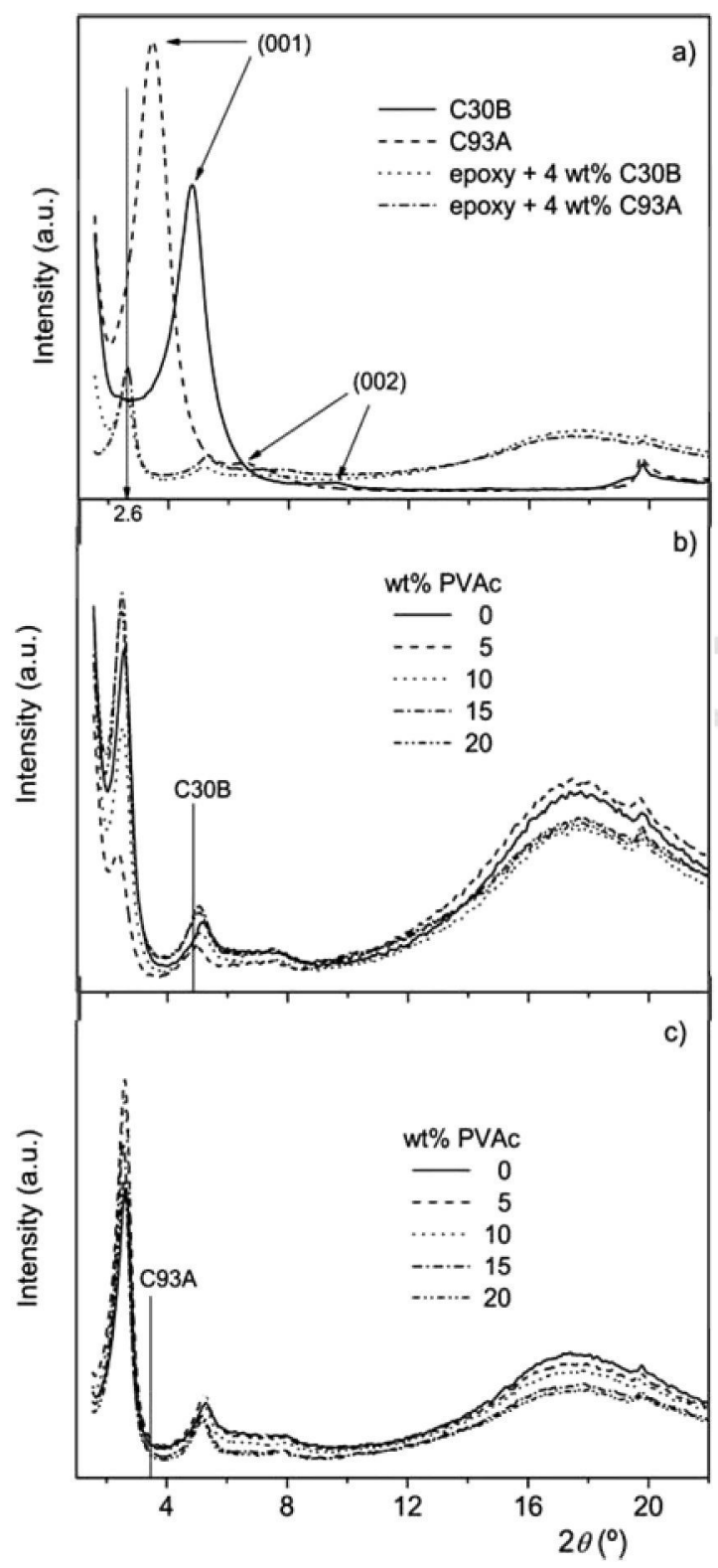

FIG. 2. WAXD patterns of: (a) C30B, C93A and epoxy/C30B and epoxy/C93A, (b) epoxy/PVAc/C30B, and (c) epoxy/PVAc/C93A nanomposites.
$2 \theta=6.50^{\circ}$ for $\mathrm{C} 93 \mathrm{~A}$ correspond to $d_{002}$ basal spacing, and the peak appearing in both clays at $19.77^{\circ}$ is assigned to the crystallographic planes (110) and (020) of the clay layers, its position being independent of the basal spacing. Figure $2 \mathrm{a}$ also shows the WAXD patterns of the epoxy/ $\mathrm{C} 30 \mathrm{~B}$ and epoxy/C93A nanocomposites. The nanocomposites exhibit $d_{001}$ basal diffraction peaks at lower $2 \theta$ values, $\left(2 \theta \sim 2.6^{\circ}\right)$ which correspond to interlayer distances of $d_{001} \sim 3.34 \mathrm{~nm}$ which are higher than those of neat clays. This indicates that nanocomposites exhibit intercalated morphology since fully exfoliated structures would be characterized by the absence of peaks in WAXD patterns. The organophilic nature of the Cloisites makes it possible for epoxy monomers to penetrate into the clay galleries. The expansion of the intragallery space, $\Delta d_{001}$, is higher in epoxy/C $30 \mathrm{~B}$ nanocomposites $\left(\Delta d_{001} \sim 1.50 \mathrm{~nm}\right)$ than in epoxy/C93A nanocomposites $\left(\Delta d_{001} \sim 0.98 \mathrm{~nm}\right)$ suggesting that epoxy molecules intercalate better in C30B than in C93A. Figure $2 b$ and $c$ show the WAXD patterns of epoxy/PVAc/C30B and epoxy/PVAc/C93A ternary nanocomposites having different contents of PVAc. As can be seen there are no great differences in the peak's positions for any of the compositions studied. Only very small increases in $d$-spacing are observed by the incorporation of PVAc (see Table 2). Similar behavior has been observed in other epoxy/thermoplastic/clay system [29]. One may conclude that the addition of PVAc does not modify the intercalated morphology. It has been suggested that in intercalated nanocomposites the alkylammonium ions reorient into the gallery, forming a paraffin-type layer structure that permits to accommodate the epoxy molecules $[1,5]$. Considering that both clays are modified with

TABLE 2. $d$-spacing $\left(d_{001}\right)$ for epoxy/PVAc/Cloisite ternary nanocomposites having $4 \mathrm{wt} \%$ of organoclay and different PVAc contents.

\begin{tabular}{lcc}
\hline & \multicolumn{2}{c}{$d_{001}(\mathrm{~nm})$} \\
\cline { 2 - 3 } wt\% PVAc & C30B $(1.85 \mathrm{~nm})$ & C93A $(2.36 \mathrm{~nm})$ \\
\hline 0 & 3.38 & 3.30 \\
5 & 3.58 & 3.34 \\
10 & 3.41 & 3.34 \\
15 & 3.48 & 3.41 \\
20 & 3.46 & 3.39 \\
\hline
\end{tabular}

The $d_{001}$ values of neat clays are given in brackets. 

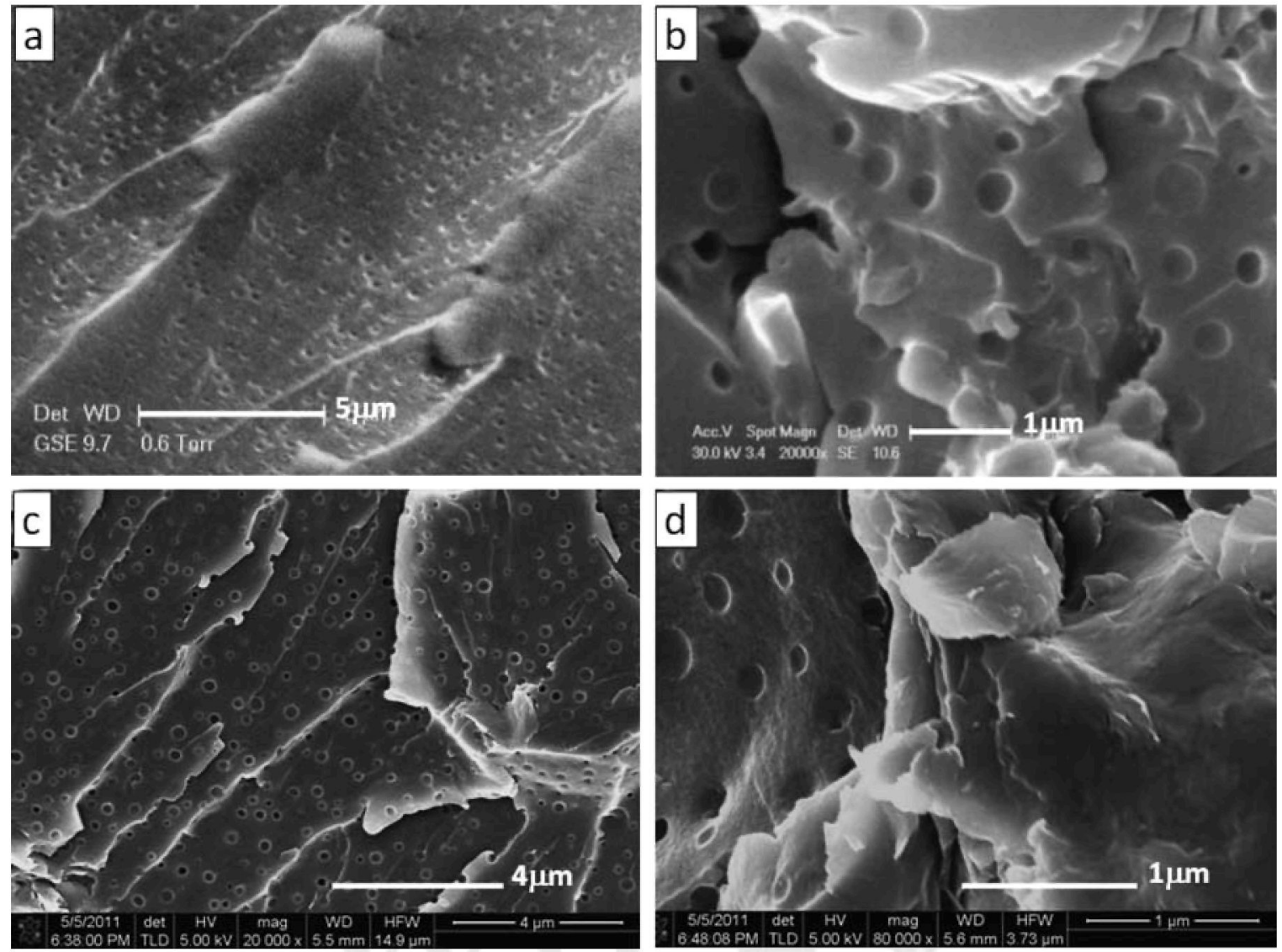

FIG. 3. SEM micrographs of: (a) epoxy $/ 5$ wt $\%$ PVAc (from Ref. 15), and of ternary nanocomposites: (b) epoxy $/ 5 \mathrm{wt} \% \mathrm{PVAc} / \mathrm{C} 30 \mathrm{~B},(\mathrm{c})$ and (d) epoxy/5 wt $\% \mathrm{PVAc} / \mathrm{C} 93 \mathrm{~A}$ at different magnifications.

alkylammonium cations of similar alkyl chain length, the similar $d$-spacing reached in $\mathrm{C} 93 \mathrm{~A}$ and $\mathrm{C} 30 \mathrm{~B}$ nanocomposites suggests a similar arrangement of alkylammonium cations compatible with a monolayer paraffin-type structure.

\section{SEM and TEM of Epoxy/PVAc/Cloisite in Cured Nanocomposites}

SEM was employed to inspect the morphology of ternary nanocomposites. In Fig. 3 micrographs of epoxy/5 wt $\%$ PVAc/C30B and epoxy/5 wt $\%$ PVAc/C93A ternary nanocomposites can be seen together with the micrograph of the binary epoxy $/ 5 \mathrm{wt} \%$ PVAc blend (Fig. 3a) taken from our previous work [16]. PVAc forms an immiscible phase in the epoxy matrix, giving rise to spherical domains. Numerous voids can be observed surrounded by stress-whitened rings similar to those observed in rubber toughened epoxies. The PVAc particles in the fractured surfaces have cavitated resulting holes, which is an energy-dissipating mechanism that improves toughness. In ternary nanocomposites containing $5 \mathrm{wt} \%$ PVAc different regions are distinguish: epoxy matrix with spherical PVAc domains and clay aggregates. The analysis of micrographs indicates that the presence of clay results in the formation of larger PVAc domains. The diameters of the PVAc domains are $100-200 \mathrm{~nm}$ in the samples having no clay [16] and $100-400 \mathrm{~nm}$ in the ternary nanocomposites. Similar behavior has been found in other epoxy systems, namely in epoxy/polyether-polyol/C30B [25] and in epoxy/hyperbranched polymer/clay [20]. It has been reported for an epoxy/rubber/clay system [24] that the presence of clay reduces the size of the rubber dispersed domains, but in that case the clay was located near the rubber domains and at the epoxy-rubber interface which prevents their coalescence. The opposite behavior shown by the systems here studied can be related to uneven distribution of the clay that, as we will discuss further, is only localized in the epoxy phase. Therefore it is reasonable to assume that the clay intercalates preferentially epoxy molecules, this would provoke an increase of the concentration of PVAc in the regions outside the clay galleries and as a consequence the phase separation leads to PVAc domains of larger size (The size of thermoplastic domains increases with the increase of their concentration). It is worth mentioning that, the size change of the PVAc domains could not be attributed to the modification of cure kinetics because the clays catalyze the curing, so that the effect would be opposite to that observed, that is, decrease of size of PVAc domains. 

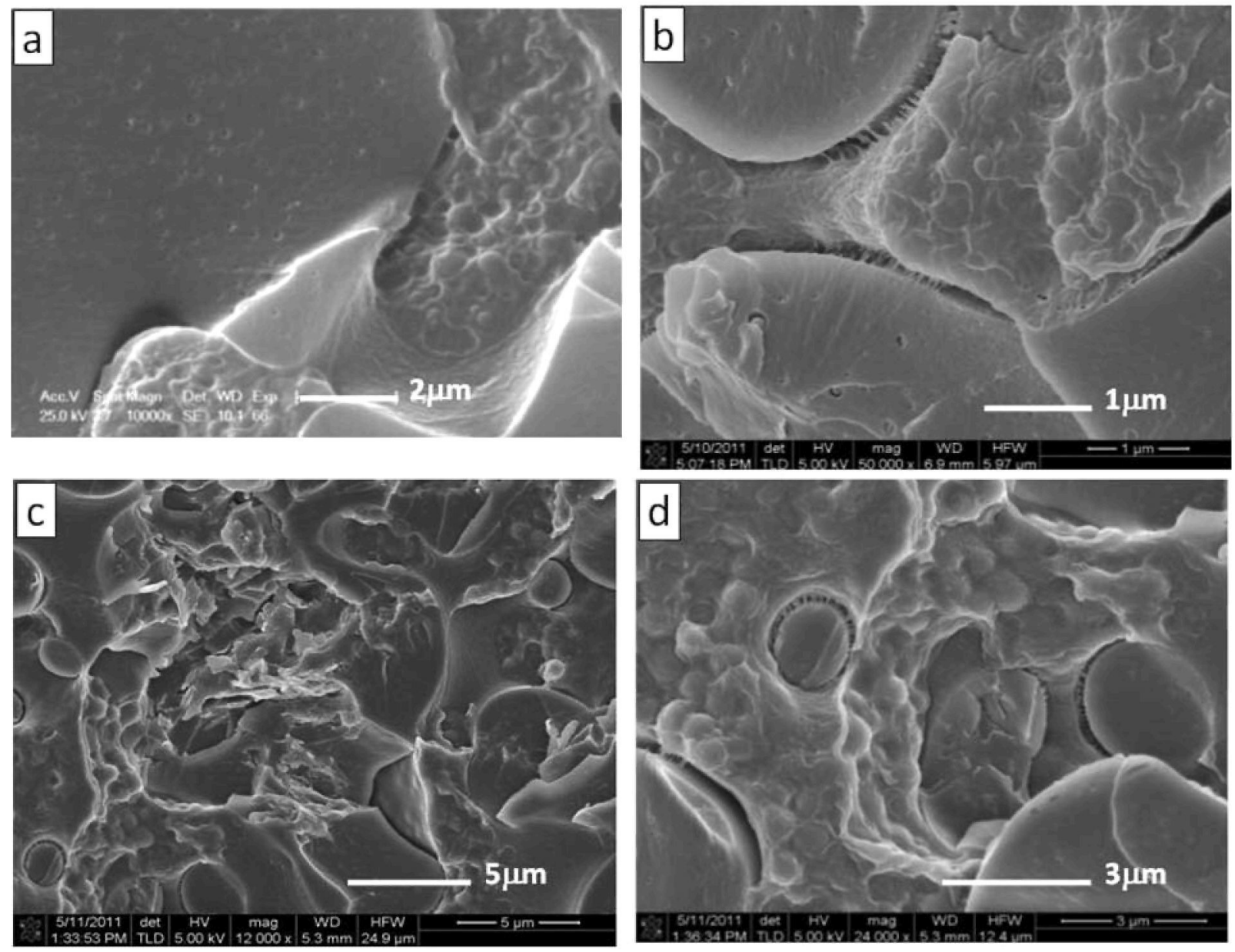

FIG. 4. SEM micrographs of: (a) epoxy/10 wt\% PVAc (from Ref. 15), (b) epoxy/10 wt \% PVAc/C93A, (c) and (d) epoxy/15 wt \% PVAc/C93A nanocomposites.

The developed morphology varied with the content of PVAc. Figure 4 shows SEM micrographs of epoxy/10 wt\% PVAc/C93A and epoxy/15 wt\% PVAc/C93A ternary nanocomposites and epoxy/10 wt \% PVAc blend (Fig. 4a). It can be observed that the samples show a combined morphology, that is, there are regions in which PVAc spheres are dispersed in the epoxy matrix (similar to epoxy $/ 5 \mathrm{wt} \%$ PVAc) combined with regions in which phase inversion appears, in these regions the epoxy phase forms spheres that are surrounded by a thin continuous PVAc phase, both regions are intertwined. All the samples having $10 \mathrm{wt} \%$ and $15 \mathrm{wt} \%$ of PVAc present combined morphology independent of the presence of clay C93A or C30B. Some agglomerates of clay can be seen together with the regions of combined morphology. It is worth to noting that in the samples that present combined morphology the nodular regions (PVAc spheres in epoxy matrix) and the inverted regions (epoxy spheres surrounded by PVAc) are held together by fibrils (see Fig. $4 \mathrm{~b}$ and $\mathrm{d}$ ). This indicates that there is some interpenetration of PVAc and epoxy at the interfaces. The combined morphology is typical of compositions close to the critical point, the samples having $10 \mathrm{wt} \%$ and $15 \mathrm{wt} \%$ of PVAc show combined morphology either with or without clay. Therefore, it reveals that although both clays accelerate the curing reaction neither of them affects significantly the reaction induced phase separation.

SEM micrographs of epoxy/20 wt $\%$ PVAc/C93A and epoxy $/ 20$ wt $\%$ PVAc/C30B are shown in Fig. 5. The morphology for this composition is completely inverted, that is, epoxy spheres surrounded by the thermoplastic-phase. The undetected clay suggests that it should be located inside the epoxy spheres, which is corroborated looking inside of the broken epoxy spheres (see Fig. 5c). In all the compositions studied there is no evidence that the PVAc intercalates into the galleries of the Cloisites, a similar behavior was observed in the system epoxy/ PMMA/C30B [26, 28, 30].

The uneven distribution of the clay was confirmed by TEM. In Figs. 6 and 7 the TEM micrographs of epoxy/ $\mathrm{C} 30 \mathrm{~B}$ and epoxy/C93A nanocomposites are reported, both show tactoids of clay with interplatelet spacing in agreement with WAXS experiments. TEM micrographs of the ternary epoxy/PVAc/clay nanocomposites are shown in Fig. 7. The samples containing $5 \mathrm{wt} \%$ of PVAc (Fig. 7a) show clay tactoids and PVAc domains dispersed in the 

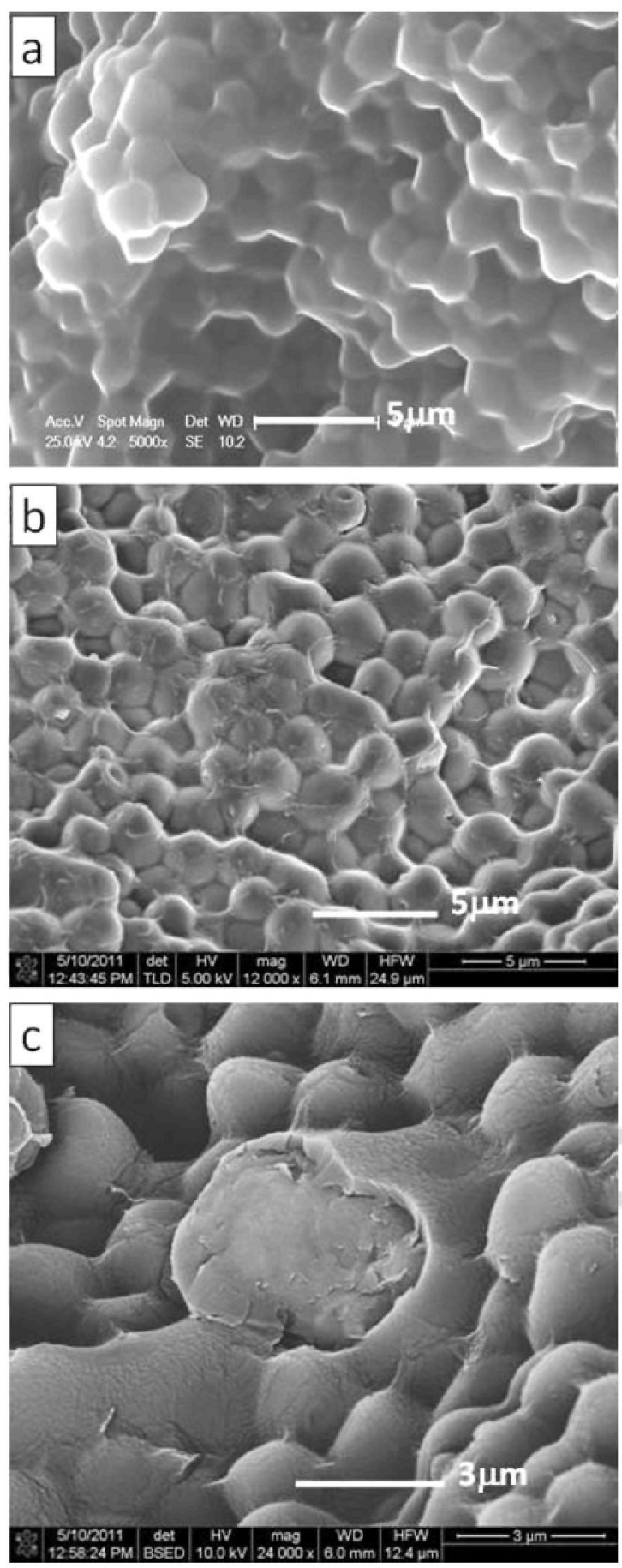

FIG. 5. SEM micrographs of: (a) epoxy/20 wt $\%$ PVAc/C30B, (b) and (c) epoxy/20 wt $\%$ PVAc/C93A at different magnifications.

epoxy matrix, the size of the PVAc domains range from 100 to $400 \mathrm{~nm}$ in agreement with SEM results. On the other hand, the samples containing $20 \mathrm{wt} \%$ of PVAc (Fig. 7b) also show clay tactoids dispersed in the epoxy phase, but the epoxy forms spheres in a matrix of PVAc as it correspond to an inverted morphology. No clay was observed in the PVAc phase, neither in nodular nor inverted morphologies. The clay nanoparticles have totally migrated to the epoxy phase. In other epoxy/ther- moplastic/clay systems the clay is also located preferentially in the epoxy phase $[26,28,30,35]$. The localization of clay particles is determined by the thermodynamics of wetting, uneven particle distribution depends on the balance of interfacial energies, $\gamma,[18]$ thus it can be concluded that $\mathrm{C} 30 \mathrm{~B}$ and $\mathrm{C} 93 \mathrm{~A}$ nanoparticles have better affinity with epoxy than with PVAc, that is $\gamma($ epoxy $/ \mathrm{C} 30 \mathrm{~B})<\gamma(\mathrm{PVAc} / \mathrm{C} 30 \mathrm{~B})$, and $\gamma($ epoxy $/ \mathrm{C} 93 \mathrm{~A})<\gamma$ (PVAc/C93A).

From these results together with WAXD ones, it can be concluded that the clay intercalated structures form tactoids always located in the epoxy phase and that the PVAc phase appears free of clay. The presence of the clay has little effect on the morphology of the epoxy/ PVAc blends (only results in a small increase of the PVAc domain size). However in other ternary nanocomposites such as epoxy/polycaprolactone/C30B [35] and epoxy/poly(ether imide)/organoclay [27] both using 4,4' diaminodiphenyl sulfone (DDS) as curing agent it has been reported that the clay has a significant influence on the reaction induced phase separation. Specifically for epoxy/polycaprolactone/C30B the combined and inverted morphologies change to nodular and combined morphologies respectively in the presence of clay. In the systems here studied the influence of clay is less evident probably due to the different interactions between components.
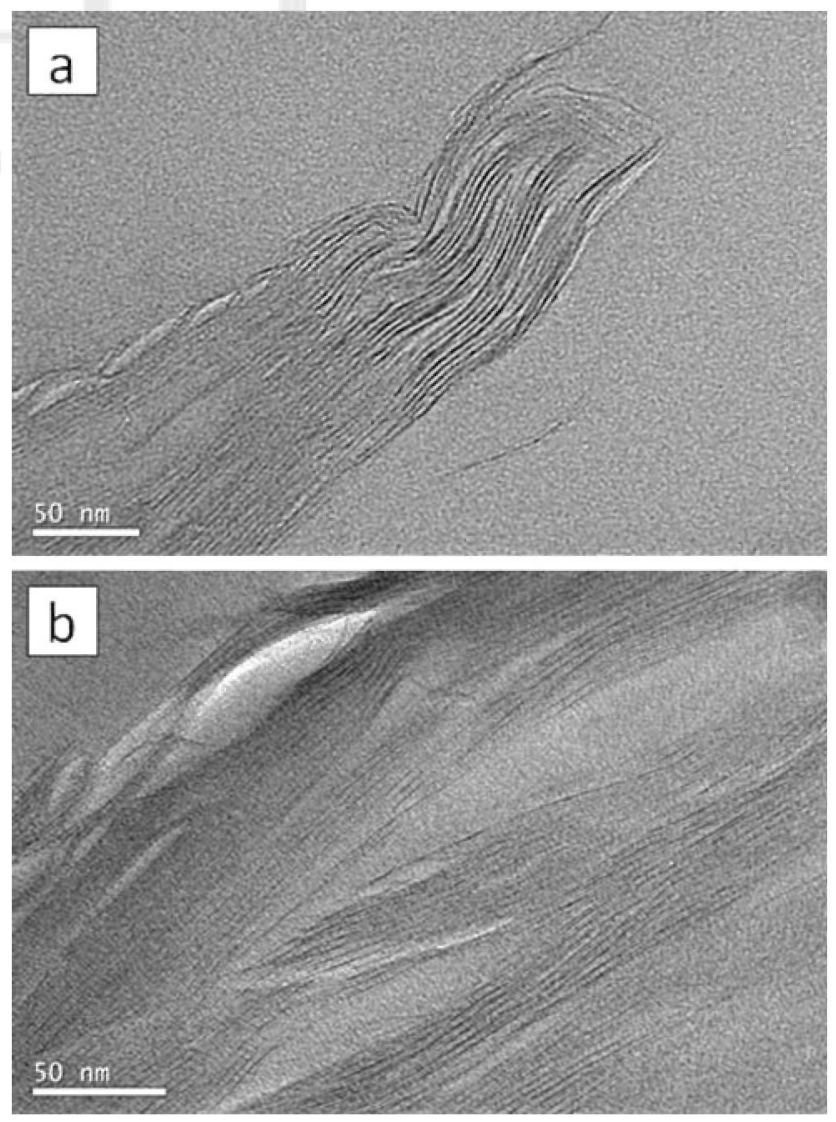

FIG. 6. TEM micrographs of: (a) epoxy/C30B and (b) epoxy/C93A nanocomposites. 

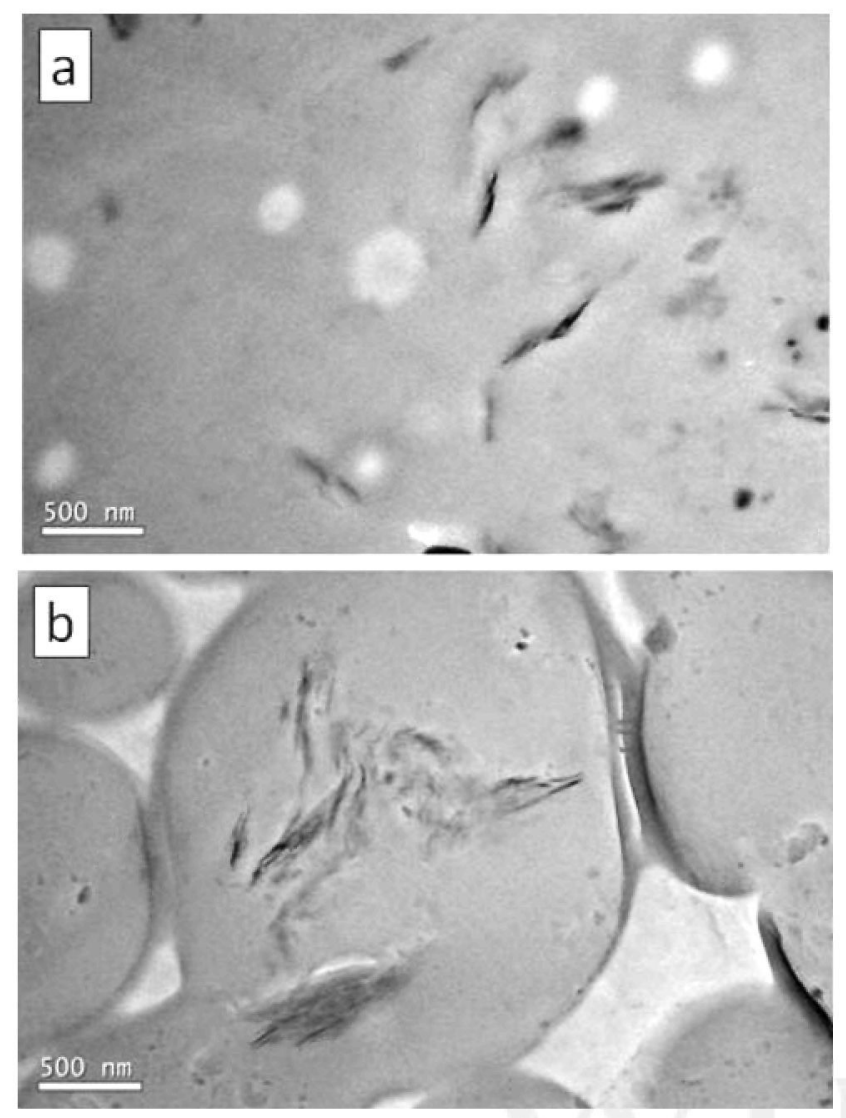

FIG. 7. TEM micrographs of: (a) epoxy/5 wt\% PVAc/C30B and (b) epoxy/20 wt $\%$ PVAc/C30B.

\section{Dynamic Mechanical Behavior of Epoxy/PVAc/Cloisite Cured Nanocomposites}

Figure 8 shows the $\tan \delta$-temperature dependence in the intervals $100-200^{\circ} \mathrm{C}$ and $30-100^{\circ} \mathrm{C}$ for epoxy/PVAc blends and for epoxy/PVAc/C30B nanocomposites. The $\tan \delta$ peak is the $\alpha$-relaxation associated to the glass transition and the temperature of the maximum at $1 \mathrm{~Hz}$ is taken as a measure of $T_{\mathrm{g}}$, these values are higher than the ones determined by DSC [16]. Two relaxations peaks are detected, one at high temperature $\left(169-170^{\circ} \mathrm{C}\right)$ due to the epoxy network and the other at $\sim 40-50^{\circ} \mathrm{C}$ corresponds to the PVAc phase. The $T_{\mathrm{g}}$ of the epoxy-rich phase in both epoxy/PVAc blends and in the nanocomposites is lower than the $T_{\mathrm{g}}$ of neat epoxy thermoset. Probably small amounts of PVAc are remaining in the epoxy matrix decreasing $T_{\mathrm{g}}$. Epoxy/PVAc/C93A and epoxy/PVAc/ C30B nanocomposites exhibit similar behaviors. Table 3 collects $T_{\mathrm{g}}$ values for the nanocomposites with $\mathrm{C} 30 \mathrm{~B}$ and with C93A, together with the $T_{\mathrm{g}}$ values of the epoxy/ PVAc blends that we have reported previously [16]. The $T_{\mathrm{g}}$ values of the epoxy phase in C93A nanocomposites and in epoxy/PVAc blends are close, while a reduction in the $T_{\mathrm{g}}$ of the epoxy phase is noticeable in $\mathrm{C} 30 \mathrm{~B}$ nanocomposites. This can be attributed to the plasticizing effect produced by the alkyl ammonium chains and to stoichiometry imbalances between DGEBA and DDM due to epoxy homopolymerization during the dispersion preparation and to preferential intercalation of DGEBA into the clay galleries [38] and these effects will be more important for the clay that undergoes greater intercalation that is C30B. The $T_{\mathrm{g}}$ of the PVAc-rich phase (see Table 3) varies with the PVAc content. For the samples with nodular morphology (5 wt $\%$ PVAc) the $T_{g}$ of the PVAcrich phase is lower than the corresponding to neat PVAc $\left(52^{\circ} \mathrm{C}\right)$. This was attributed to tension stresses around the PVAc small particles which arise during cooling after curing (owing to the differences in expansion coefficient between epoxy matrix and PVAc [16]) like it occurs in
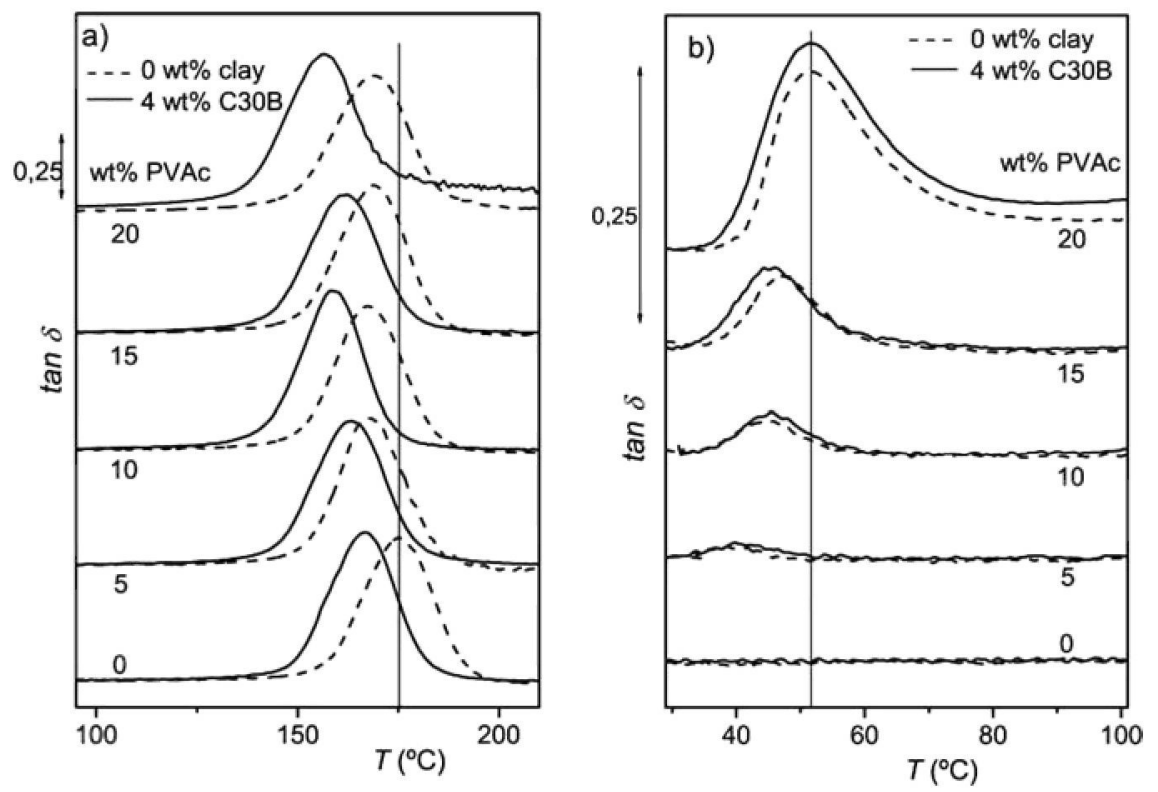

FIG. 8. Tan $\delta$ vs. temperature for epoxy/PVAc blends (dash line) and for epoxy/PVAc/C30B nanocomposites (solid line) with different PVAc contents: (a) from 100 to $200^{\circ} \mathrm{C}$ and (b) from 30 to $100^{\circ} \mathrm{C}$. 
TABLE 3. $T_{\mathrm{g}}$ values from DMTA for epoxy/PVAc blends, and for epoxy/PVAc/C30B and epoxy/PVAc/C93A nanocomposites with different PVAc contents.

\begin{tabular}{|c|c|c|c|c|c|c|}
\hline \multirow[b]{2}{*}{$\begin{array}{l}\text { wt \% } \\
\text { PVAc }\end{array}$} & \multicolumn{3}{|c|}{$T_{\mathrm{g}}$ epoxy $(\mathrm{C})$} & \multicolumn{3}{|c|}{$T_{\mathrm{g}} P V A C\left({ }^{\circ} \mathrm{C}\right)$} \\
\hline & $\begin{array}{l}0 \% \\
\text { clay }^{\mathrm{a}}\end{array}$ & $\begin{array}{l}4 \mathrm{wt} \% \\
\text { C30B }\end{array}$ & $\begin{array}{l}4 \mathrm{wt} \% \\
\mathrm{C} 93 \mathrm{~A}\end{array}$ & $\begin{array}{l}0 \% \\
\text { clay }^{\mathrm{a}}\end{array}$ & $\begin{array}{l}4 \mathrm{wt} \% \\
\mathrm{C} 30 \mathrm{~B}\end{array}$ & $\begin{array}{l}4 \mathrm{wt} \% \\
\mathrm{C} 93 \mathrm{~A}\end{array}$ \\
\hline 0 & 175 & 167 & 172 & - & - & - \\
\hline 5 & 168 & 164 & 173 & 39 & 40 & 39 \\
\hline 10 & 167 & 165 & 170 & 44 & 43 & 47 \\
\hline 15 & 169 & 162 & 170 & 47 & 44 & 47 \\
\hline 20 & 169 & 157 & 169 & 52 & 51 & 52 \\
\hline 100 & - & - & - & 52 & - & - \\
\hline
\end{tabular}

${ }^{\mathrm{a}}$ From Ref. [16].

rubber-modified epoxies [39]. For totally inverted morphologies (20 wt $\%$ PVAc) the $T_{\mathrm{g}}$ of the PVAc-rich phase reaches the value of neat PVAc. Moreover, the $T_{\mathrm{g}}$ of the PVAc-rich phase remains almost unchanged with the addition of clay in all the samples studied. This reflects that the clay does not perturb the relaxation of the PVAc whatever the morphology of the system.

From the temperature of the maximum of $\tan \delta$ measured at different frequencies $(1,2,6,10$, and $40 \mathrm{~Hz})$ using Arrhenius plot (log frequency vs. 1/temperature of $\tan \delta$ maximum) the apparent activation energies, $E_{\mathrm{a}}$, of the relaxations were evaluated. For the epoxy phase the $E_{\mathrm{a}}$ values obtained were $620 \pm 30 \mathrm{~kJ} \mathrm{~mol}^{-1}$ in epoxy/ PVAc blends [16], $630 \pm 50 \mathrm{~kJ} \mathrm{~mol}^{-1}$ in epoxy/PVAc/ $\mathrm{C} 30 \mathrm{~B}$ nanocomposites and $620 \pm 60 \mathrm{~kJ} \mathrm{~mol}^{-1}$ in epoxy/ PVAc/C93A nanocomposites. No changes were detected in the apparent activation energy of the epoxy phase relaxation with the presence of clay neither with the presence of PVAc. In the same way for the PVAc phase the $E_{\mathrm{a}}$ values obtained were $340 \pm 20 \mathrm{~kJ} \mathrm{~mol}^{-1}$ in epoxy/ PVAc blends, $350 \pm 40 \mathrm{~kJ} \mathrm{~mol}^{-1}$ in epoxy/PVAc/C30B nanocomposites and $390 \pm 40 \mathrm{~kJ} \mathrm{~mol}^{-1}$ in epoxy/PVAc/ C93A nanocomposites without detecting significant differences between the studied compositions.

The storage modulus $\left(E^{\prime}\right)$ vs. temperature curves were also obtained in DMTA experiments. The values of $E^{\prime}$ at $33^{\circ} \mathrm{C}$ are given in Table 4. At this temperature both PVAc and epoxy are below $T_{\mathrm{g}}$ (glassy state). From Table

TABLE 4. Storage modulus at $33^{\circ} \mathrm{C}$ (glassy state) for epoxy/PVAc/ $\mathrm{C} 30 \mathrm{~B}$ and epoxy/PVAc/C93A nanocomposites with different PVAc contents.

\begin{tabular}{lccc}
\hline \multicolumn{3}{c}{$E^{\prime}(\mathrm{GPa})$} \\
\hline wt\% PVAc & $0 \%$ clay & 4 wt\% C30B & 4 wt\% C93A \\
\hline 0 & 1.56 & 1.81 & 1.63 \\
5 & 1.38 & 1.59 & 1.39 \\
10 & 1.36 & 1.54 & 1.47 \\
15 & 1.38 & 1.71 & 1.52 \\
20 & 1.46 & 1.79 & 1.49 \\
\hline
\end{tabular}

4 it can de deduced that the incorporation of clay increases the storage modulus, specifically the moduli of epoxy/PVAc/C30B nanocomposites are significantly higher than that of the neat epoxy thermoset. The good $E^{\prime}$ results obtained for $\mathrm{C} 30 \mathrm{~B}$ nanocomposites (in comparison with those of C93A nanocomposites) are correlated with the larger intercalation of epoxy into $\mathrm{C} 30 \mathrm{~B}$ galleries previously discussed. It should be noted that it is difficult to improve rigidity of highly crosslinked (high $T_{\mathrm{g}}$ ) epoxies by forming nanocomposites.

The loss modulus vs. temperature plots for epoxy/ PVAc/C30B nanocomposites are shown in Fig. 9. The curves have two peaks located at low $\left(39-48^{\circ} \mathrm{C}\right)$ and high $\left(143-155^{\circ} \mathrm{C}\right)$ temperatures, these peaks are related to the relaxations of the PVAc and the epoxy phases respectively. Interestingly, in these systems the intensity of the $E^{\prime \prime}$ relaxations not only depends on the amount and nature of the phase that relax, but also on the morphology, as we have reported previously for binary systems: epoxy/ PVAc [16] and for epoxy/poly(benzyl methacrylate) [17]. Namely, in epoxy/PVAc blends the height of the $E^{\prime \prime}$ peaks, $H E^{\prime \prime}$, corresponding to PVAc relaxation is proportional to the PVAc content, but the $H E^{\prime \prime}$ of the epoxy relaxation sharply decreases for inverted morphologies (20 wt\% PVAc). This behavior is also shown by the ternary systems epoxy/PVAc/C93A nanocomposites, as it is illustrates in Fig. 10 that shows $H E^{\prime \prime}$ as a function of the PVAc content for the epoxy and PVAc relaxations in the nanocomposites. Loss modulus is a measure of the energy dissipated as heat per cycle and it is related to the viscous response of the material. The samples with inverted

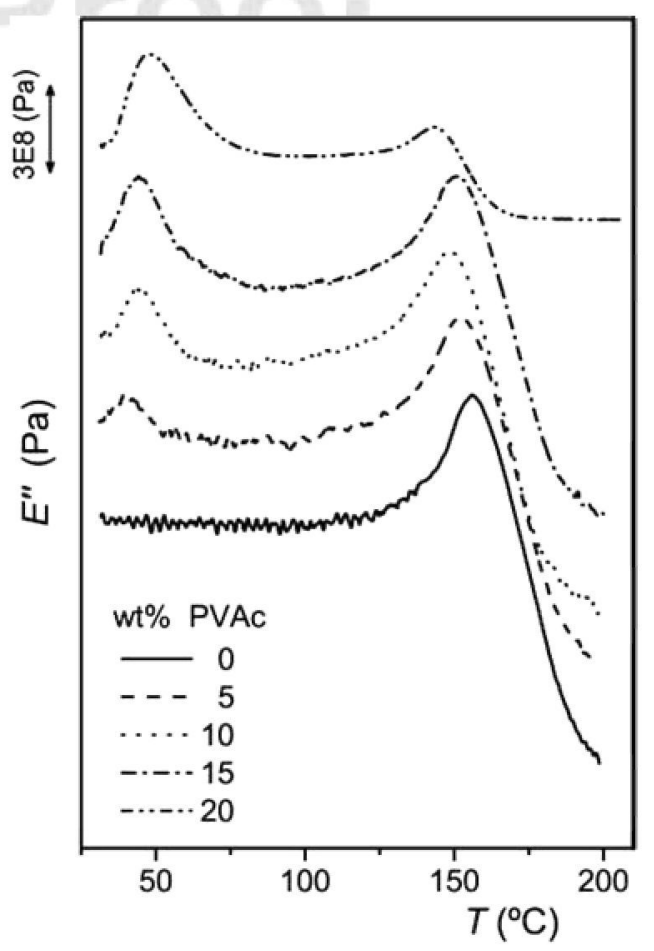

FIG. 9. $\mathrm{E}^{\prime \prime}$ vs. temperature from 30 to $220^{\circ} \mathrm{C}$ for epoxy/PVAc/C30B nanocomposites with different PVAc contents. 


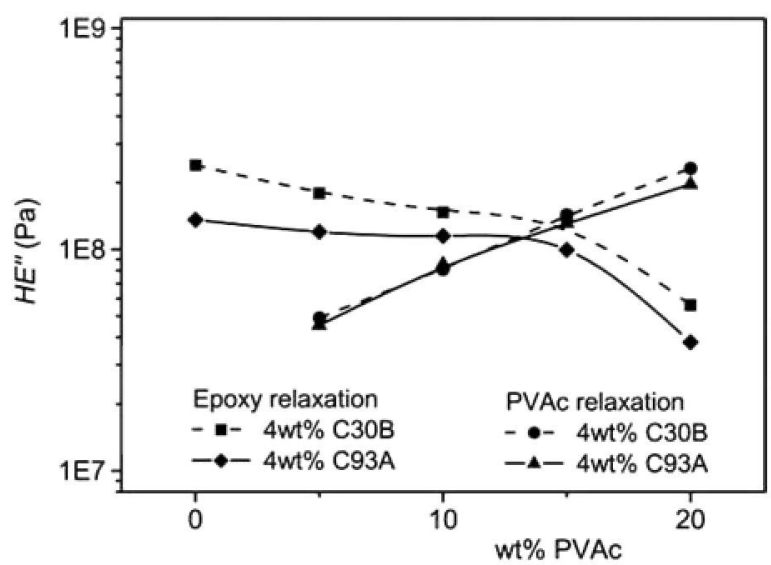

FIG. 10. Relaxation peaks height, $H E^{\prime \prime}$, as a function of PVAc content for the epoxy relaxation in epoxy/PVAc/C30B and in epoxy/PVAc/ C39A nanocomposites, and for the PVAc relaxation in epoxy/PVAc/ $\mathrm{C} 30 \mathrm{~B}$ and in epoxy/PVAc/C39A nanocomposites.

morphologies are constituted by epoxy spheres surrounded by a thermoplastic (PVAc) phase and the temperature at which the epoxy relaxation occurs is well above the PVAc $T_{\mathrm{g}}$, which would explain the sudden $H E^{\prime \prime}$ drop of the epoxy relaxation in inverted morphologies.

\section{Mechanical Tensile Properties of Epoxy/PVAc/Cloisite Nanocomposites}

The tensile properties of nanocomposites were determined by stress-strain measurements in tensile loading. To illustrate the tensile behavior Fig. 11 shows the stress-strain curves for neat epoxy, neat PVAc, epoxy/10 wt $\%$ PVAc blend, epoxy $/ 10$ wt $\%$ PVAc/C30B, and epoxy/10 wt $\%$ PVAc/C39A nanocomposites. The stress increased with strain until it reached a maximum value followed by ultimate failure, the stress show linear dependence with strain only at low strain values. The stress-strain curves evidence that both PVAc and epoxy exhibit fragile behavior whereas the epoxy/PVAc blends show ductile behavior. From the curves the values of tensile modulus $E$, tensile strength (stress at break), strain at break and area under stress-strain curves which is a mea-

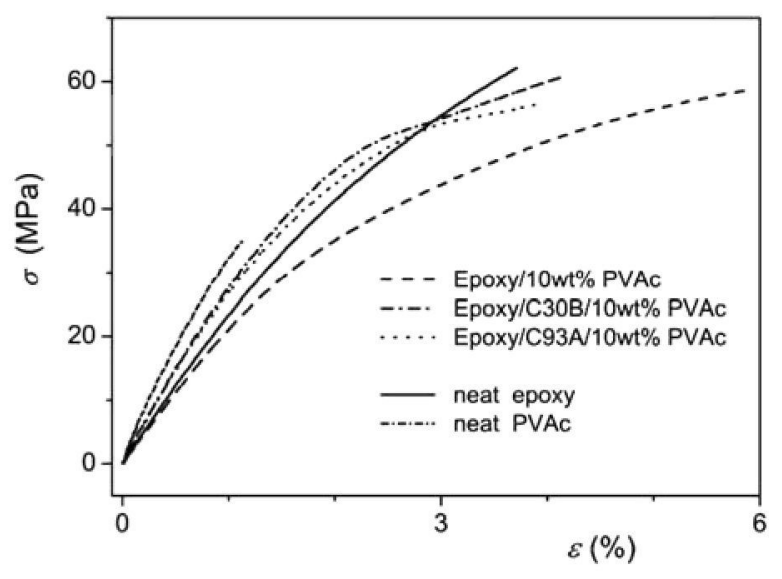

FIG. 11. Stress-strain curves for: neat epoxy, neat PVAc, epoxy/10 wt\% PVAc, epoxy/10 wt $\%$ PVAc/C30B and epoxy/10 wt $\%$ PVAc/ C39A.

sure of the toughness were calculated. Tensile test results represent average values from six or more test samples. Table 5 collects the tensile results of epoxy/PVAc/C30B and epoxy/PVAc/C39A at different PVAc contents together with those obtained previously for epoxy/PVAc blends [16]. As usual the values of tensile modulus are higher than the values of the storage modulus [16] but the trend is similar. The epoxy/PVAc samples with nodular and combined morphologies have tensile modulus close to that of the neat epoxy, and the tensile modulus of samples with inverted morphologies (not included in Table 5) approaches to that of PVAc. The tensile modulus of the nanocomposites epoxy/PVAc/C30B and epoxy/PVAc/ C39A is higher than of the epoxy/PVAc blends (increments: $20-36 \%$ for $\mathrm{C} 30 \mathrm{~B}$ and $12-32 \%$ for $\mathrm{C} 93 \mathrm{~A}$ ) evidencing the reinforcing action of the clay.

The tensile strength values hardly change with $\mathrm{C} 30 \mathrm{~B}$ loading, though show a decrease with C93A loading. An increase in strength is expected when strong adhesion takes place between components in a composite material. Accordingly, the decrease in tensile strength in epoxy/ PVAc/C93A nanocomposites suggests that the interfacial strength between the organoclay and the matrix is weaker than in epoxy/PVAc/C30B nanocomposites. The load

TABLE 5. Stress-strain results for: epoxy/PVAc/C30B and epoxy/PVAc/C39A with different PVAc contents.

\begin{tabular}{|c|c|c|c|c|c|c|}
\hline & \multicolumn{3}{|c|}{ Tensile modulus (GPa) } & \multicolumn{3}{|c|}{ Tensile strength $(\mathrm{MPa})$} \\
\hline wt $\%$ PVAc & $0 \%$ Clay $^{\mathrm{a}}$ & $4 \mathrm{wt} \% \mathrm{C} 30 \mathrm{~B}$ & 4 wt $\%$ C93A & $0 \%$ clay $^{\mathrm{a}}$ & 4 wt\% C30B & $4 \mathrm{wt} \% \mathrm{C} 93 \mathrm{~A}$ \\
\hline 0 & $2.5 \pm 0.2$ & $3.0 \pm 0.2$ & $2.8 \pm 0.1$ & $63 \pm 4$ & $65 \pm 4$ & $54 \pm 3$ \\
\hline 5 & $2.4 \pm 0.2$ & $3.0 \pm 0.2$ & $2.7 \pm 0.1$ & $62 \pm 3$ & $57 \pm 4$ & $52 \pm 7$ \\
\hline 10 & $2.2 \pm 0.2$ & $3.0 \pm 0.2$ & $2.9 \pm 0.2$ & $59 \pm 2$ & $60 \pm 4$ & $56 \pm 4$ \\
\hline 100 & $4.1 \pm 0.5$ & - & - & $37 \pm 3$ & - & - \\
\hline \multirow[t]{2}{*}{$w t \%$ PVAc } & \multicolumn{3}{|c|}{ Strain at break $(\%)$} & \multicolumn{3}{|c|}{ Estimated toughness by tensile curve $\left(\mathrm{MJ} / \mathrm{m}^{3}\right)$} \\
\hline & $0 \%$ clay $^{a}$ & $4 \mathrm{wt} \% \mathrm{C} 30 \mathrm{~B}$ & $4 \mathrm{wt} \% \mathrm{C} 93 \mathrm{~A}$ & $0 \%$ clay $^{\mathrm{a}}$ & $4 \mathrm{wt} \% \mathrm{C} 30 \mathrm{~B}$ & $4 \mathrm{wt} \% \mathrm{C} 93 \mathrm{~A}$ \\
\hline 0 & $3.7 \pm 0.7$ & $3.4 \pm 0.3$ & $2.9 \pm 0.3$ & $137 \pm 35$ & $130 \pm 20$ & $95 \pm 15$ \\
\hline 5 & $4.4 \pm 0.5$ & $3.1 \pm 0.2$ & $3.0 \pm 0.8$ & $170 \pm 30$ & $110 \pm 20$ & $81 \pm 25$ \\
\hline 10 & $5.9 \pm 0.5$ & $4.1 \pm 0.7$ & $3.8 \pm 0.8$ & $230 \pm 50$ & $165 \pm 50$ & $150 \pm 40$ \\
\hline 100 & $1.3 \pm 0.3$ & - & - & $28 \pm 9$ & - & - \\
\hline
\end{tabular}

${ }^{\mathrm{a}}$ From ref. [16]. 
transfer between the reinforcement phase (clay) and the epoxy matrix is less efficient in epoxy/PVAc/C93A than in epoxy/PVAc/C30B.

As can be seen in Table 5 the strain at break and the toughness of PVAc at $22^{\circ} \mathrm{C}$ are very low, this is the typical behavior of non ductile thermoplastic below $T_{\mathrm{g}}$. The neat epoxy thermoset has higher toughness than PVAc although it is not enough for some applications like matrices of composite materials. However there is a synergic effect in ductility and toughness of the epoxy/PVAc blends [16]. The strain at break and toughness of epoxy are improved up to $60 \%$ and $70 \%$ respectively by adding $10 \mathrm{wt} \%$ PVAc. The addition of clays to the epoxy and to the epoxy/PVAc blends leads to a reduction of the strain at break and toughness which is slightly greater for C93A nanocomposites. It has been reported for some polymer/ clay nanocomposites a reduction of strain at break and toughness respect to the neat polymer [13]. The results here reported show that the presence of clay embrittles the epoxy thermoset but the addition of PVAc improves toughness. Accordingly epoxy/5 wt $\%$ PVAc/C30B and epoxy/5 wt $\%$ PVAc/C93A nanocomposites exhibited lower strain at break and toughness than neat epoxy thermoset but epoxy/10 wt \% PVAc/C $30 \mathrm{~B}$ and epoxy/10 wt $\%$ PVAc/C93A exhibited higher strain at break and toughness than neat epoxy thermoset. It is known that polymer blends with co-continuous structures have improved toughness as compared with blends with nodular morphology [16] this is the behavior plainly showed by epoxy/10 wt $\%$ PVAc/Cloisite nanocomposites here studied.

\section{CONCLUSIONS}

The effect of organoclay nanoparticles on the morphology, thermal and mechanical properties of ternary epoxy/ PVAc/Cloisite nanocomposites was studied. Ternary nanocomposites were prepared using two organoclays: $\mathrm{C} 30 \mathrm{~B}$ and $\mathrm{C} 93 \mathrm{~A}$, with 4 wt $\%$ of clay and varying the PVAc content from 0 to $20 \mathrm{wt} \%$.

DSC results showed that the curing behavior was modified by the presence of clay either PVAc, the clays accelerated the cure kinetics while PVAc slowed it.

WAXS revealed that all the nanocomposites present intercalated structures and that the addition of PVAc did not change the basal spacing.

Morphology of the nanocomposites was examined in detail by SEM and TEM. Curing induced phase separation takes place in epoxy/PVAc/C30B and in epoxy/ PVAc/C93A nanocomposites, leading to different types of morphologies (nodular, combined, and inverted) as a function of the PVAc content. The presence of clay do not change the morphology of the epoxy/PVAc blends, only small differences were detected in the size of the dispersed phase in nodular morphologies. The clay nanoparticles are unevenly distributed they are only contained in the epoxy phase and are not observed inside PVAc phase, independently of the sample morphology.

DMTA revealed that the $T_{\mathrm{g}}$ of the epoxy phase decreases with respect to both PVA $_{\mathrm{C}}$ and Cloisite $30 \mathrm{~B}$ content, however the presence of clays do not influence the $T_{\mathrm{g}}$ of the PVAc phase.

The presence of $\mathrm{C} 30 \mathrm{~B}$ and $\mathrm{C} 93 \mathrm{~A}$ nanoparticles improves Young's modulus but decreases the toughness of epoxy thermoset and epoxy/PVAc blends. The incorporation of PVAc into the epoxy thermoset improves toughness but causes a decrease of the Young's modulus. We conclude that the addition of $\mathrm{C} 30 \mathrm{~B}$ and PVAc (10 wt\%) to epoxy achieves a good balance of modulus and toughness in ternary nanocomposites that exhibit combined morphology.

\section{NOMENCLATURE}

CEC Cation exchange capacity

DDM 4,4'-Diamino diphenylmethane

DDS 4,4'-Diaminodiphenyl sulfone

DGEBA Diglycidyl ether of bisphenol A

DMTA Dynamic Mechanical Thermal Analysis

DSC Differential Scanning Calorimetry

MMT Montmorillonite

PVA $_{C} \quad$ Poly(vinyl acetate)

SEM Scanning electron microscopy

TEM Transmission electron microscopy

WAXD Wide-Angle X-Ray Diffraction

\section{REFERENCES}

1. S.C. Tjong, Mater. Sci. Eng. R, 53, 73 (2006).

2. S. Pavlidou and C. Papaspyrides, Prog. Polym. Sci., 33, 1119 (2008).

3. D.R. Paul and L.M. Robeson, Polymer, 49, 3187 (2008).

4. P.B. Messersmith and E.P. Giannelis, Chem. Mater., 6, 1719 (1994).

5. T. Lan, P.D. Kaviratna, and T.J. Pinnavaia, J. Phys. Chem. Solids, 57, 1005 (1996).

6. X. Kornmann, H. Lindberg, and L.A. Berglund, Polymer, 42, 1303 (2001).

7. J.H. Park and S.C. Jana, Macromolecules 36, 8391 (2003).

8. J.H. Park and S.C. Jana SC, Polymer 45, 7673 (2004).

9. M.C. Richardson, J. Kim, D. Ho, C.R. Smyder, N.A. Dsouza, and G.A. Holmes, Polym. Compos., 32, 67 (2011).

10. F. Román, S. Montserrat, and J.M. Hutchinson, J. Therm. Anal. Calorim., 87, 113 (2007).

11. P.I. Xidas and K.S. Triantafyllidis, Eur. Polym. J., 46, 404 (2010).

12. T.D. Ngo, M.T. Ton-That, S.V. Hoa, and K.C. Cole, Polym. Eng. Sci., 52, 607 (2012).

13. A.A. Azeez, K.Y. Rhee, S.J. Park, and D. Hui, Compos. Part B, 45, 308 (2013).

14. J.P. Pascault, H. Sautereau, J. Verdu, and R.J.J. Williams, Thermosetting Polymers, Marcel Dekker, New York, 226 (2002). 
15. M.I. Giannotti, I. Mondragón, M.J. Galante, and P.A. Oyanguren, Polym. Int., 54, 897 (2005).

16. M. Sánchez-Cabezudo, R.M. Masegosa, C. Salom, and M.G. Prolongo, J. Therm. Anal. Calorim., 102, 1025 (2010).

17. M.G. Prolongo, C. Arribas, C. Salom, and R.M. Masegosa, Polym. Eng. Sci., 50, 1820 (2010).

18. F. Fenouillot, P. Cassagnau, and J.C. Majesté, Polymer, 50, 1333 (2009).

19. Y.S. Lipatov, T.D. Ignatova, L.F. Kosyanchuk, and N.V. Yarovaya, Eur. Polym. J., 42, 3102 (2006).

20. D. Ratna, O. Becker, R. Krishnamurthy, G.P. Simon, and R.J. Varley, Polymer, 44, 7449 (2003).

21. S. Balakrishnan, P.R. Start, D. Raghavan, and S.D. Hudson, Polymer, 46, 11255 (2005).

22. B.T. Marouf, R.A. Pearson, and R. Bagheri, Mater. Sci. Eng. A, 515, 49 (2009).

23. N.Y. Yuhana, S. Ahmad, M.R. Kamal, S.C. Jana, and A.R.S. Bahri, J. Nanomater., 39, 1 (2012).

24. P.P. Vijayan, D. Puglia, J.M. Kenny, and S. Thomas, Soft. Matter., 9, 2899 (2013).

25. I. Isik, U. Yilmazer, and G. Bayram, Polymer, 44, 6371 (2003).

26. J.H. Park and S.C. Jana, Polymer, 44, 2091 (2003).

27. M. Peng, H. Li, L. Wua, Y. Chen, Q. Zheng, and W. Gu, Polymer, 46, 7612 (2005).
28. M. Hernandez, B. Sixou, J. Duchet, and H. Sautereau, Polymer, 48, 4075 (2007).

29. A. Asif, V.L. Rao, V. Saseendran, and K.N. Ninan, Polym. Eng. Sci., 49, 756 (2009).

30. M. Hernandez, J. Duchet-Rumeau, and H. Sautereau, $J$. Appl. Polym. Sci., 118, 3632 (2010).

31. A. Mirmohseni and S. Zavareh, J. Polym. Res., 17, 191 (2010).

32. Y. Wang, X. Ma, and B. Zhang, Polym. Compos., in press.

33. Y. Wang, B. Zhang, and J. Ye, Mater. Sci. Eng. A, 528,7999 (2011).

34. M. Bashar, U. Sundararaj, and P. Mertiny, Compos. Part A, 43, 945 (2012).

35. J. Rotrekl, L. Matejka, L. Kapralkova, A. Zhigunov, J. Hromadkpva, and I. Kelnar, Exp. Polym. Lett., 6, 975 (2012).

36. M. Sánchez-Cabezudo, M.G. Prolongo, C. Salom, and R.M. Masegosa, J. Therm. Anal. Calorim., 86, 699 (2006).

37. M.G. Prolongo, F.J. Martínez-Casado, R.M. Masegosa, and C. Salom, J. Nanosci. Nanotech., 10, 2870 (2010).

38. M.A. García del Cid, M.G. Prolongo, C. Salom, C. Arribas, M. Sánchez-Cabezudo, and R.M. Masegosa, J. Therm. Anal. Calorim., 108, 741 (2012).

39. D. Verchere, J.P. Pascault, H. Sautereau, S.M. Moschiar, and C.C.Ricardi, J. Appl. Polym. Sci., 42, 701 (1991). 